\title{
Endoscopic submucosal dissection with double-clip traction for recurrent adenoma
}

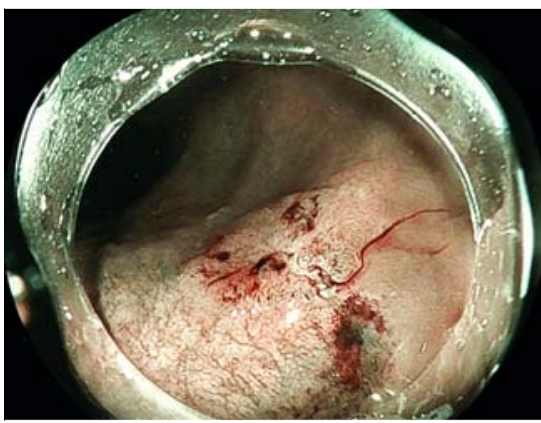

- Fig. 1 Recurrence after endoscopic mucosal resection.

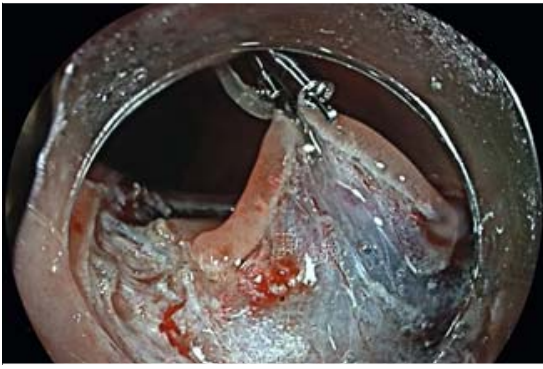

Fig. 2 Double-clip traction.

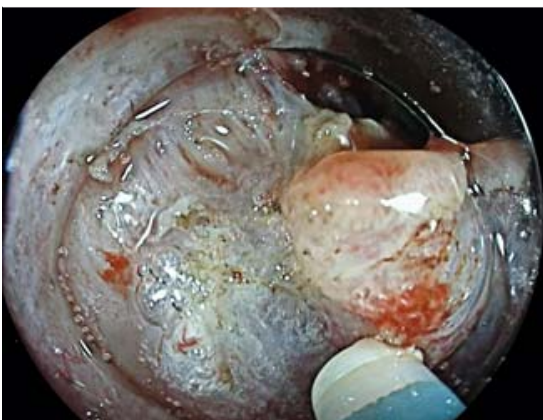

- Fig. 3 Endoscopic submucosal dissection of the fibrotic area.

The adenoma recurrence rate is $10 \%$ $30 \%[1,2]$ after piecemeal resection of the colorectum, making this a particularly challenging type of lesion for endoscopic resection. Underwater endoscopic mucosal resection (EMR), full-thickness resection [3], and "cold avulsion snare

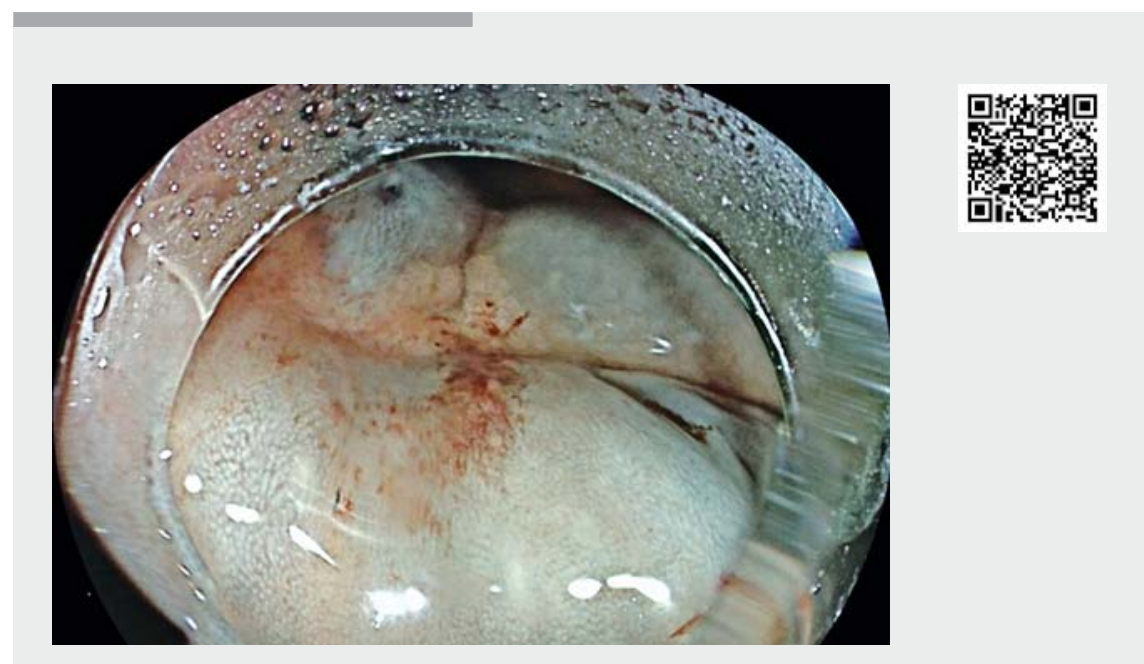

$\checkmark$ Video 1 Endoscopic submucosal dissection with double clip traction for recurrent adenoma.

type coagulation" have been demonstrated as potentially effective endoscopic procedures in Western countries. In Japan, endoscopic submucosal dissection (ESD) is the first-line treatment for recurrent adenoma but is difficult to perform owing to the high degree of fibrosis. In Europe, colorectal ESD is unpopular for treating such lesions because of the difficulties associated with recurrence. We report a case of rapid ESD of a 15-mm recurrent adenoma of the colon. This lesion was considered to be recurrent following 4-cm piecemeal EMR with three endoscopic failures (one of classic EMR and two of argon plasma coagulation) ( Fig. 1). The lesion was clearly identified on the right side of the scar. The submucosa was injected with glycerol without elevation of the lesion. The mucosa was incised using a Dual Knife J (Olympus, Tokyo, Japan), away from the lesion, to identify the submucosal plane. After initial submucosal dissection, our previously reported double-clip traction ESD method (DCT-ESD) [4] was performed on the rectal side of the lesion ( $\triangleright$ Fig. 2, $\triangleright$ Video 1 ), with clear distinction between normal submucosa and the fibrotic area. The fibrotic area was dissected using Endocut I (ERBE, Tübingen, Germany) to increase accuracy and avoid retraction due to the coagulation current ( $\vee$ Fig. 3 ). Good exposure of the area facilitated rapid and safe dissection. Complete ESD of a 25$\mathrm{mm}$ specimen was achieved in $10 \mathrm{~min}$ utes. The pathological analysis confirmed successful R0 resection of a low-grade adenoma with dysplasia.

DCT-ESD is an efficient procedure with a high success rate for endoscopic resection of complex recurrent adenomas. An ongoing multicenter French study aims to validate our results.

Endoscopy_UCTN_Code_TTT_1AQ_2AD

\section{Competing interests}

The authors declare that they have no conflict of interest. 
The authors

Jérémie Albouys ${ }^{1}$, Sophie Geyl ${ }^{1}$, Anne Guyot ${ }^{2}$, Aurélie Charissoux ${ }^{2}$, Romain Legros ${ }^{1}$, Mathieu Pioche $^{3}$, Jérémie Jacques ${ }^{1}$

1 Gastroentérologie et Endoscopie Digestive, CHU Dupuytren, Limoges, France

2 Anatomopathologie, CHU Dupuytren, Limoges, France

3 Unité d'Endoscopie Digestive, Service de Gastroentérologie, Pavillon H, Hôpital Edouard Herriot, Hospices Civils de Lyon, Lyon, France

\section{Corresponding author}

Jérémie Albouys, MD

Service d'Hépatogastroentérologie, $\mathrm{CHU}$

Dupuytren 87042, Limoges, France

Fax: +33-5-55058733

jeremie.albouys@gmail.com

\section{References}

[1] Tate DJ, Desomer L, Klein A et al. Adenoma recurrence after piecemeal colonic EMR is predictable: the Sydney EMR recurrence tool. Gastrointest Endosc 2017; 85: 647656.e6

[2] Belderbos TDG, Leenders M, Moons LM et al. Local recurrence after endoscopic mucosal resection of nonpedunculated colorectal lesions: systematic review and meta-analysis. Endoscopy 2014; 46: 388-402

[3] Andrisani G, Soriani P, Manno M et al. Colorectal endoscopic full-thickness resection (EFTR) with the over-the-scope device $\left(\right.$ FTRD $\left.^{\circledR}\right)$ : a multicenter Italian experience. Dig Liver Dis 2019; 51: 375-381

[4] Jacques J, Charissoux A, Bordillon P et al. High proficiency of colonic endoscopic submucosal dissection in Europe thanks to countertraction strategy using a double clip and rubber band. Endosc Int Open 2019; 7: E1166-E1174
Bibliography

Endoscopy 2020; 52: E439-E440

DOI 10.1055/a-1158-8518

ISSN 0013-726X

published online 12.5.2020

(c) 2020. Thieme. All rights reserved.

Georg Thieme Verlag KG, Rüdigerstraße 14, 70469 Stuttgart, Germany

\section{ENDOSCOPY E-VIDEOS \\ https://eref.thieme.de/e-videos}

口回 Endoscopy E-Videos is a free rection, reporting 自: on interesting cases and new techniques in gastroenterological endoscopy. All papers include a high quality video and all contributions are freely accessible online.

This section has its own submission website at

https://mc.manuscriptcentral.com/e-videos 